\title{
ASXL1 gene alterations in patients with isolated 20q deletion
}

\author{
J. BREZINOVA ${ }^{1}$, I. SAROVA ${ }^{1}$, K. SVOBODOVA ${ }^{2}$, H. LHOTSKA ${ }^{2}$, S. RANSDORFOVA ${ }^{1}$, S. IZAKOVA ${ }^{2}$, L. PAVLISTOVA ${ }^{2}$, L. LIZCOVA ${ }^{2}$, K. SKIPALOVA ${ }^{2}$, \\ L. HODANOVA ${ }^{2}$, J. MARKOVA ${ }^{3}$, Z. ZEMANOVA ${ }^{2}$, J. CERMAK ${ }^{3}$, A. JONASOVA ${ }^{4}$, K. MICHALOVA ${ }^{2}$ \\ ${ }^{1}$ Department of Cytogenetics, Institute of Hematology and Blood Transfusion, Prague, Czech Republic; ${ }^{2}$ Center of Oncocytogenetics, Institute \\ of Medical Biochemistry and Laboratory Diagnostics, General University Hospital and First Faculty of Medicine, Charles University in Prague, \\ Prague, Czech Republic; ${ }^{3}$ Clinical Department, Institute of Hematology and Blood Transfusion, Prague, Czech Republic; ${ }^{4} 1$ st Medical Depart- \\ ment, General University Hospital and First Faculty of Medicine, Charles University in Prague, Prague, Czech Republic
}

*Correspondence: jana.brezinova@uhkt.cz

Received October 10, 2018 / Accepted January 15, 2019

\begin{abstract}
Deletion 20q is a recurrent abnormality in myeloid malignancies. In our previous study, we identified fusion of additional sex combs-like 1 (ASXL1) and teashirt zinc finger homeobox 2 genes in a patient with myelodysplastic syndrome. The objective of this study was to determine the frequency of ASXL1 breakpoints in a cohort of 36 patients with deletion $20 \mathrm{q}$ as the sole cytogenetic aberration. A combination of molecular cytogenetic methods was used to confirm ASXL1 gene alterations in 19 of the 36 patients and the determination of $A S X L 1$ gene changes in patients with deletion 20q revealed clinical and prognostic impacts.
\end{abstract}

Key words: ASXL1, FISH, deletion 20q, myelodysplastic syndrome, molecular cytogenetics

Deletion of the long arm of chromosome $20[\operatorname{del}(20 \mathrm{q})]$ in bone marrow cells represents a common chromosomal abnormality associated with myeloid malignancies, in particular myelodysplastic syndromes (MDSs), acute myeloid leukemia (AML) and myeloproliferative neoplasms (MPNs) [1]. The deletion is most frequently interstitial and highly variable in size. As reported previously, proximal breakpoints are located in the 20q11.21-q12 region and distal breakpoints span from 20q13.13 to 20q13.33 and several commonly deleted regions have been identified in MDS, MPN and MDS/MPN patients [2]. Deletion 20q as the sole aberration is associated with a favorable outcome; such patients have considerably longer survival compared with other MDS patients [3]. In our previous study, we showed a fusion of additional sex combs-like 1 (ASXL1) and teashirt zinc finger homeobox 2 genes that resulted in an isochromosome of deleted 20q - ider(20q) in a patient with MDS [4]. ASXL1 is located on 20q11.21 (30,946,155-31,027,122 forward strand hg19/GRCh37-Feb_2009) and mutations of this gene are generally associated with poor prognosis across the spectrum of hematologic malignancies as reviewed in Alvarez et al. [5]. Majority of the mutations are located in exon 12; however, rare mutations have been detected in the other exons of ASXL1 [6].
Our objective was to determine the frequency of ASXL1 alterations in $\operatorname{del}(20 \mathrm{q})$ cases, to characterize breakpoints in the ASXL1 gene using microarray techniques [array comparative genomic hybridization (aCGH)] and to evaluate the difference in survival between patients with and those without $A S X L 1$ alteration.

\section{Patients and methods}

Fluorescence in situ hybridization (FISH) using locus specific-probes for 20q11, 20q12 and 20q13.12 regions (Abbott, Des Plaines, IL, USA; Kreatech Diagnostics, Amsterdam, The Netherlands; MetaSystems, Altlussheim, Germany) was performed to confirm cytogenetically observed deletions of $20 \mathrm{q}$ in a cohort of 36 patients (27 males, 9 females, median age at diagnosis: 68 years) with hematologic disorders: MDSs $(n=21)$, MPNs $(n=10)$, non-Hodgkin lymphomas $(\mathrm{n}=2)$, acute myeloid leukemia $(\mathrm{n}=1)$, thrombocytopenia $(\mathrm{n}=1)$ and anemia $(\mathrm{n}=1)$. In all patients, deletion of $20 \mathrm{q}$ was the sole cytogenetic aberration, no other cytogenetic changes were found; however, in three patients a variant of del $(20 \mathrm{q})$, an isochromosome of deleted 20q, was detected. All patients provided informed consent for use of their samples for research purposes. Metaphase 
Table 1. Clinical data and aCGH results in a cohort of eight patients with breakpoints in the ASXL1 gene and with partial deletion of the 3 ' end of the gene.

\begin{tabular}{|c|c|c|c|c|c|}
\hline $\begin{array}{l}\text { Pat. } \\
\text { No. }\end{array}$ & Sex & Age & Diagnosis & aCGH findings & $\begin{array}{r}\text { Survival } \\
\text { (months) }\end{array}$ \\
\hline $1^{*}$ & $\mathrm{M}$ & 79 & MDS & $\begin{array}{l}\operatorname{arr}[\text { GRCh37] 20pterp11.1(60770_25755060)x1,20p11.1q11.21(25805264_30954484)x3, } \\
\text { 20q11.21q13.2(30960195_52045077)x1,20q13.2qter(52097649_62949120)x3 }\end{array}$ & 22 \\
\hline 2 & M & 78 & MDS & $\operatorname{arr}[$ GRCh37] 20q11.21q13.13(30948635_49457826)x1 & 50 \\
\hline 3 & M & 75 & Thrombocytopenia & $\operatorname{arr}[$ GRCh37] 20q11.2q13.13(31018764_49797610)x1 & 8 \\
\hline 4 & M & 77 & MDS & $\operatorname{arr}[$ GRCh37] 20q11.21q13.2(31006521_50759886)x1 & 7 \\
\hline 5 & M & 64 & MPN & $\operatorname{arr}[$ GRCh37] 20q11.21q13.13(31001393_49205106)x1 & $39+$ \\
\hline 6 & M & 63 & MDS & $\operatorname{arr}[$ GRCh37] 20q11.21q13.13(31012919_49629926)x1 & $40+$ \\
\hline 7 & M & 64 & MDS & $\operatorname{arr}[$ GRCh37] 8q11.21qter(48770702_143562095)x2 hmz,20q11.21q13.13(30954773_49507643)x1 & 50 \\
\hline 8 & M & 74 & MPN & $\operatorname{arr}[$ GRCh37] 20q11.21q13.2(31001594_51764010)x1 & unknown \\
\hline
\end{tabular}

M: male; MDS: myelodysplastic syndromes; MPN: myeloproliferative neoplasms; ${ }^{\star}$ Patient with ider(20q); + Patient is still alive

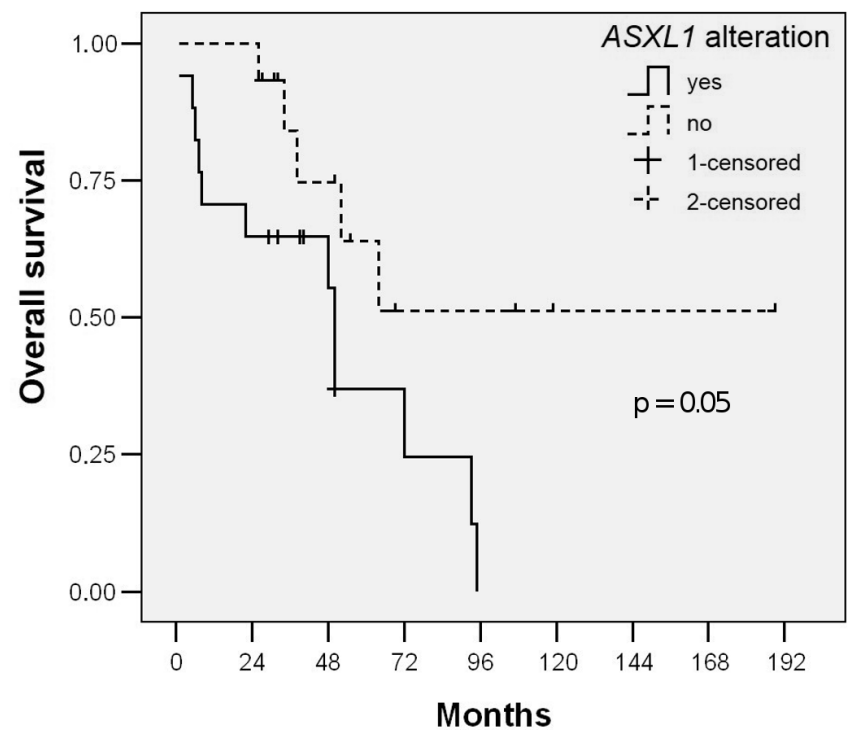

Figure 1. Kaplan-Meier survival curves for patients with and without ASXL1 gene alterations. Kaplan-Meier survival curves proved significant differences (overall survival 48.6 and 119.0 months, respectively; $p=0.05$ ) between these two groups.

FISH mapping using a set of five bacterial artificial chromosome (BAC) probes (RP11-600A9, RP1-316I5, RP11-358N2, RP4-669H2 and RP5-823G15, BlueGnome, Cambridge, UK; Empire Genomics Buffalo, NY, USA) that target sequences in 20q11.21 and 20q13.2, along with a chromosome-20-specific centromeric probe (Kreatech Diagnostics) as a control, were used for determination of the breakpoints. BACs RP11-358N2 (chr20: 30,938,520-31,115,717) and RP11-600A9 (chr20: 30,927,178-31,082,065) completely cover the ASXL1 gene.

aCGH [CytoChip Cancer 4x180K, CytoChip Cancer SNP 4x180K (Illumina, San Diego, CA, USA); SurePrint G3 Cancer CGH+SNP Microarray 4x180K (Agilent, Santa Clara, CA, USA)] was performed on DNA samples from bone marrow cells derived from eight patients with suspected partial deletions in ASXL1 to characterize the breakpoints.
Kaplan-Meier survival analyses were performed using Mantel-Cox, Breslow and Tarone-Ware tests.

\section{Results}

According to the FISH results, three groups of patients were established: (1) 8 patients (22\%; males only) had a proximal breakpoint in ASXL1 with partial deletion of the gene; (2) 11 patients (31\%; 9 males, 2 females) had complete deletion of ASXL1; and (3) 17 patients (47\%; 10 males, 7 females) had no alterations in either copy of ASXL1, with the proximal breakpoint of the deletion located downstream of this gene. In summary, the ASXL1 gene was altered (partially or completely deleted) in 19 of the 36 patients (53\%; 17 males, 2 females). aCGH confirmed a high heterogeneity of the breakpoints in ASXL1, with the most common frequency in/ downstream of the exon 4 and with partial deletion of the $3^{\prime}$ end of the gene (Table 1). Of the 19 patients with ASXL1 alteration, $12(63 \%)$ died and of the 17 patients with no such alterations, 5 (29\%) died. Kaplan-Meier survival curves for the patient groups with and without ASXL1 gene alterations showed significant differences (overall survival 48.6 and 119.0 months, respectively; $\mathrm{p}=0.05$, this is a threshold value for statistical significance, Figure 1). No significant difference in age between these two groups was found $(\mathrm{p}=0.126)$.

\section{Discussion}

Deletion $20 \mathrm{q}$ is a recurrent cytogenetic abnormality frequently found in bone marrow cells of MDS patients and when present as a sole cytogenetic aberration, it represents a favorable outcome according to IPSS-R (Revised International Prognostic Scoring System; [7]). In our study deletion of $20 \mathrm{q}$ was the sole cytogenetic aberration; however, in three patients, a variant of del(20q), an isochromosome of deleted $20 q-\operatorname{ider}(20 q)$, was detected. This isochromosome is a subtle rearrangement that is difficult to recognize using classical cytogenetics and the prognosis is unclear due to the small number of cases reported $[8,9]$. Several mutations recently 
discovered by new technologies often significantly affect the prognosis of MDS patients. ASXL1 is the second most frequently mutated gene in MDSs after TET2 [10]. Many studies have identified ASXL1 gene mutations in myeloid malignancies as unfavorable prognostic indicators (reviewed in [5]). Schnittger et al. [11] reported associations of ASXL1 mutations with male sex and older age in AML patients. Similarly, a male predominance was also found in our study, the group with ASXL1 alterations comprised of 17 males and only 2 females, compared with 10 males and 7 females in the group without ASXL1 alterations. However, we did not detect a significant difference in age between these two groups $(\mathrm{p}=0.126)$. ASXL1 alterations are most often frameshift, nonsense or missense mutations. Missense mutations lead to a change in one amino acid of a protein, leaving the rest of the amino acid sequence unaffected. Frameshift and nonsense mutations lead to a premature stop codon, resulting in a truncated and usually non-functional protein [5]. Truncated ASXL1 proteins caused by frameshift or nonsense mutations were associated with a significantly worse overall survival, compared with wild type ASXL1 or ASXL1 harboring a point mutation, among patients with chronic myelomonocytic leukemia or MDS [12-15]. We assume that the same association (ASXL1 protein truncation and worse survival) occurs in patients with MDS and deletion 20q with breakpoints in/upstream of ASXL1 causing partial/whole deletion of this gene. In our cohort of 36 patients with del(20q), the whole gene was deleted in 11 patients and partially deleted in 8 patients. The breakpoints in ASXL1 gene were heterogeneous with high recurrence in/downstream of exon 4 and with loss of the $3^{\prime}$ end of the gene. We also found a shorter survival of patients with ASXL1 partial/total deletion compared with patients with no ASXL1 alterations (48.6 vs. 119.0 months; $\mathrm{p}=0.05$ ). However, not only truncation of the gene but also haploinsufficiency for loss of the whole gene may contribute to the disease progression. Only a few studies have focused on the ASXL1 role in patients with 20q deletion. Bacher et al. [16] detected ASXL1 gene deletion by aCGH in 10 of 30 patients (33.3\%) selected randomly from a cohort of 305 patients with MDS and del(20q); whole ASXL1 deletion was found in nine cases and a partial deletion in one case. Similarly, Huh et al. [17] identified 20q deletions in 23 of 1162 patients with MDS, MPN or AML using single nucleotide polymorphism array (SNP-A) and of those, 10 harbored del(20q11.21), corresponding specifically to the ASXL1 locus. The authors suggested that ASXL1 loss of function might contribute significantly to the pathogenesis of hematopoietic diseases. Our results support these findings; however, the number of cases with ASXL1 deletion was higher in our cohort (53\% of patients; complete deletion in 11 and partial deletion in 8 cases). Based on the results of our study we assume that total/partial ASXL1 gene deletion contributes to worse prognosis in patients with del(20q). In all patients with the breakpoint in ASXL1 gene the 3' end of the gene and exon 12 were lost and we hypothesized that the expression of this gene was downregulated. These results correspond with published data that ASXL1 mutations associated with myeloid neoplasms display a truncation in exon 12 [18-20] and that there is a loss of ASXL1 protein expression when ASXL1 mutations are detected in myeloid neoplasms [20]. The ASXL1 mutation status is important in patients with a low or intermediate risk of MDS, as the difference in survival is significantly different between patients carrying an ASXL1 mutation and those with wild type ASXL1. Notably, ASXL1 mutations did not seem to have a prognostic impact in patients with a higher risk of MDSs based on the FrenchAmerican-British and/or World Health Organization classification $[10,13]$. We also showed a significant difference in the survival of patients with del(20q) and low risk of MDS according to IPSS-R [7], between with and without ASXL1 alteration. Different techniques are used to identify the ASXL1 alterations, of which next generation sequencing is the most common followed by Sanger sequencing. In our cohort of patients, FISH using specific BAC probes was used to identify ASXL1 alteration and aCGH was used to confirm all partial ASXL1 deletions identified by FISH. We consider FISH using specific BAC probes to be a reliable and robust technique that can readily detect $A S X L 1$ alterations in routine analyses of del(20q) patients. Identifying such alterations in cases with a low risk of MDS may have a clinical and prognostic impact and may help identify those patients who need to be monitored more carefully and more frequently than those without this genetic alteration.

Acknowledgements: The authors thank all of their colleagues at the Cytogenetic Department of the Institute of Hematology and Blood Transfusion and at the Centre of Oncocytogenetics, Institute of Medical Biochemistry and Laboratory Diagnostics, General University Hospital and 1st Faculty of Medicine of Charles University in Prague, Czech Republic as well as Ing. A. Dohnalova for performing the statistical analyses. This work was supported by Ministry of Health, Czech Republic - conceptual development of research organization (Institute of Hematology and Blood Transfusion, 00023736), RVO-VFN64165, GACR P302/12/G157, Progres Q28/LF1.

\section{References}

[1] SWERDLOW SH, CAMPO E, HARRIS NL, JAFFE ES, PILERI SA et al (Eds.). WHO classsification of tumours of haematopoietic and lymphoid tissues, revised 4th Edition. IARC, Lyon 2017, p 586. ISBN 9789283244943

[2] WU C, PAN J, QIU H, XUE Y, CHEN S et al. Microarray CGH analysis of hematological patients with del(20q). Int J Hematol 2015; 102: 617-625. https://doi.org/10.1007/ s12185-015-1872-3

[3] SCHANZ J, TUCHLER H, SOLE F, MALLO M, LUNO E et al. New comprehensive cytogenetic scoring system for primary myelodysplastic syndromes (MDS) and oligoblastic acute myeloid leukemia after MDS derived from an international database merge. J Clin Oncol 2012; 30: 820-829. https://doi.org/10.1200/JCO.2011.35.6394 
[4] BREZINOVA J, SAROVA I, BURYOVA H, MARKOVA J, RANSDORFOVA $S$ et al. Fusion of the additional sex combs like 1 and teashirt zinc finger homeobox 2 genes resulting from ider(20q) aberration in a patient with myelodysplastic syndrome. Br J Haematol 2014; 164: 153-155. https://doi. org/10.1111/bjh.12586

[5] ALVAREZ ARGOTE J, DASANU CA. ASXL1 mutations in myeloid neoplasms: pathogenetic considerations, impact on clinical outcomes and survival. Curr Med Res Opin 2018; 34: 757-763. https://doi.org/10.1080/03007995.2016.1276896

[6] INOUE D, MATSUMOTO M, NAGASE R, SAIKA M, FUJINO T et al. Truncation mutants of ASXL1 observed in myeloid malignancies are expressed at detectable protein levels. Exp Hematol; 2016; 44: 172-176. https://doi.org/10.1016/j. exphem.2015.11.011

[7] GREENBERG PL, TUECHLER H, SCHANZ J, SANZ G, GARCIA-MANERO G et al. Revised international prognostic scoring system for myelodysplastic syndromes. Blood 2012; 120: 2454-2465. https://doi.org/10.1182/ blood-2012-03-420489

[8] DOUET-GUILBERT N, LAI JL, BASINKO A, GUEGANIC $\mathrm{N}$, ANDRIEUX $\mathrm{J}$ et al. Fluorescence in situ hybridization characterization of ider(20q) in myelodysplastic syndrome. Br J Haematol 2008; 143: 716-720. https://doi.org/10.1111/ j.1365-2141.2008.07436.x

[9] MULLIER F, DALIPHARD S, GARAND R, DEKEYSER $\mathrm{M}$, CORNET Y et al. Morphology, cytogenetics, and survival in myelodysplasia with del(20q) or ider(20q): a multicenter study. Ann Hematol 2012; 91: 203-213. https://doi. org/10.1007/s00277-011-1286-0

[10] BEJAR R, STEVENSON K, ABDEL-WAHAB O, GALILI N, NILSSON B et al. Clinical effect of point mutations in myelodysplastic syndromes. N Engl J Med 2011; 364: 2496-2506. https://doi.org/10.1056/NEJMoa1013343

[11] SCHNITTGER S, EDER C, JEROMIN S, ALPERMANN T, FASAN A et al. ASXL1 exon 12 mutations are frequent in AML with intermediate risk karyotype and are independently associated with an adverse outcome. Leukemia 2013; 27: 82-91. https://doi.org/10.1038/leu.2012.262

[12] GELSI-BOYER V, TROUPLIN V, ROQUAIN J, ADELAIDE J, CARBUCCIA $\mathrm{N}$ et al. ASXL1 mutation is associated with poor prognosis and acute transformation in chronic myelomonocytic leukaemia. Br J Haematol 2010; 151: 365-375. https://doi.org/10.1111/j.1365-2141.2010.08381.x
[13] CHEN TC, HOU HA, CHOU WC, TANG JL, KUO YY et al. Dynamics of ASXL1 mutation and other associated genetic alterations during disease progression in patients with primary myelodysplastic syndrome. Blood Cancer J 2014; 4: e177. https://doi.org/10.1038/bcj.2013.74

[14] PATNAIK MM, ITZYKSON R, LASHO TL, KOSMIDER O, FINKE CM et al. ASXL1 and SETBP1 mutations and their prognostic contribution in chronic myelomonocytic leukemia: a two-center study of 466 patients. Leukemia 2014; 28: 2206-2212. https://doi.org/10.1038/leu.2014.125

[15] THOL F, FRIESEN I, DAMM F, YUN H, WEISSINGER EM et al. Prognostic significance of ASXL1 mutations in patients with myelodysplastic syndromes. J Clin Oncol 2011; 29: 2499-2506. https://doi.org/10.1200/JCO.2010.33.4938

[16] BACHER U, HAFERLACH T, SCHNITTGER S, ZENGER $\mathrm{M}$, MEGGENDORFER $\mathrm{M}$ et al. Investigation of $305 \mathrm{pa}-$ tients with myelodysplastic syndromes and 20q deletion for associated cytogenetic and molecular genetic lesions and their prognostic impact. Br J Haematol 2014; 164: 822-833. https://doi.org/10.1111/bjh.12710

[17] HUH J, TIU RV, GONDEK LP, O’KEEFE CL, JASEK M et al. Characterization of chromosome arm $20 \mathrm{q}$ abnormalities in myeloid malignancies using genome-wide single nucleotide polymorphism array analysis. Genes Chromosomes Cancer 2010; 49: 390-399. https://doi.org/10.1002/ gcc. 20748

[18] GELSI-BOYER V, TROUPLIN V, ADELAIDE J, BONANSEA J, CERVERA N et al. Mutations of polycomb-associated gene ASXL1 in myelodysplastic syndromes and chronic myelomonocytic leukaemia. Br J Haematol 2009; 145: 788-800. https://doi.org/10.1111/j.1365-2141.2009.07697.x

[19] CARBUCCIA N, MURATI A, TROUPLIN V, BRECQUEVILLE M, ADELAiDE J et al. Mutations of ASXL1 gene in myeloproliferative neoplasms. Leukemia 2009; 23: 2183 2186. https://doi.org/10.1038/leu.2009.141

[20] ABDEL-WAHAB O, ADLI M, LAFAVE LM, GAO J, HRICIK T et al. ASXL1 mutations promote myeloid transformation through loss of PRC2-mediated gene repression. Cancer Cell 2012; 22: 180-193. https://doi.org/10.1016/j. ccr.2012.06.032 